\title{
A formação acadêmico-profissional no Serviço Social brasileiro*
}

\section{Academic and professional training in the Brazilian Social Work}

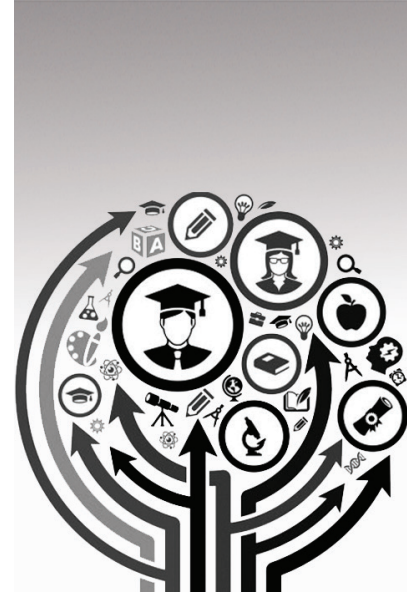

Marilda Villela lamamoto**

Resumo: O propósito deste texto é fazer uma leitura crítica das diretrizes curriculares para o curso de Serviço Social, inscritas na história recente da sociedade brasileira, considerando-as como fruto de determinantes histórico-sociais e da ação dos sujeitos profissionais. E apontar alguns de seus avanços, impasses e desafios contemporâneos. A ênfase recai sobre a articulação entre formação e trabalho do assistente social, privilegiando as mudanças operadas na política pública de ensino superior e as metamorfoses ocorridas no mercado de trabalho numa época de crise do capital sob a égide das finanças.

Palavras-chave: Serviço Social no Brasil. Ensino superior. Formação em Serviço Social

\begin{abstract}
The aim of this article is to do a critical reading of the curriculum guidelines for the graduation course in Social Work, as they are enrolled in the current history of the Brazilian society, and they also result both from historical and social determinants and from the professionals' action. Its contemporary advances, impasses and challenges are pointed too. The emphasis is on the articulation between the social worker's training and work, focusing on the changes in the public policies for the graduation courses, and in the labor market in times of crisis of the capital under the aegis of finance.
\end{abstract}

Keywords: Social Work in Brazil. Graduation course. Training in Social Work.

* Texto base da conferência pronunciada no VII Seminário Anual de Serviço Social promovido pela Cortez Editora, realizado no Tuca, em São Paulo, no dia 12 de maio de 2014. Agradeço à Cortez Editora e, em particular, à assessoria editorial da área de Serviço Social, a honra do convite para participar na mesa de abertura do $7^{\circ}$ Seminário Anual de Serviço Social: Formação e trabalho profissional do assistente social nos marcos do capitalismo contemporâneo: resistências, conquistas e desafios conjunturais, partilhada com o prof. dr. José Paulo Netto e a profa. dra. Maria Lúcia Carvalho.

** Professora titular da Universidade do Rio de Janeiro (Uerj), professora titular aposentada da Universidade Federal do Rio de Janeiro (UFRJ), pesquisadora do CNPq e do Programa de Incentivo à Produção Científica, Técnica e Artística — Prociência — da Uerj, Rio de Janeiro/RJ, Brasil. E-mail: mviamamoto@ uol.com.br. 


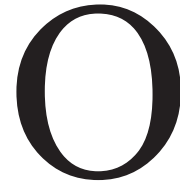
$\mathrm{s}$ assistentes sociais brasileiros vêm contradizendo a naturalização da ordem do capital nesses tempos de aridez de projetos de futuro, afirmando a radicalidade da aposta humana na construção da história. Como já dizia um filósofo alemão: "Ser radical é tomar as coisas pela raiz. Mas a raiz, para o homem, é o próprio homem” (Marx, 1974, p. 8).

Há mais de três décadas, nos moldes da "grande política", vimos recusando a nos aprisionar nas teias dos fetiches do capital nesses tempos de hegemonia das finanças. Com base na economia política do trabalho e da aliança com as forças progressistas, acenamos a bandeira da luta política, que dá alento e esperança à construção histórica de outra forma de organização da vida social que possa a vir contemplar o desenvolvimento de cada um e de todos os indivíduos sociais.

\section{Quadro atual do Serviço Social brasileiro}

Desde a década de 1980, vimos afirmando ser o Serviço Social uma especialização do trabalho da sociedade, inscrita na divisão social e técnica do trabalho social, o que supõe afirmar o primado do trabalho na constituição dos indivíduos sociais. Esta orientação é distinta da prioridade do mercado, tão cara aos liberais. Indagamos sobre significado social do Serviço Social no processo de produção e reprodução das relações sociais, numa perspectiva de totalidade histórica (Iamamoto, in Iamamoto e Carvalho, 1982).

Reafirma-se a dimensão contraditória das demandas e requisições sociais que se apresentam à profissão, expressão das forças sociais que nelas incidem: tanto $o$ movimento do capital quanto os direitos, valores e princípios que fazem parte das conquistas e do ideário dos trabalhadores (Iamamoto, in Iamamoto e Carvalho, 1982; Abess, 1986).

As condições que circunscrevem o trabalho do assistente social expressam a dinâmica das relações sociais vigentes na sociedade. O exercício profissional é necessariamente polarizado pela trama das relações e interesses sociais e participa tanto dos mecanismos de exploração e dominação quanto, ao mesmo tempo e pela mesma atividade, de respostas institucionais e políticas às necessidades de sobrevivência das classes trabalhadoras e da reprodução do antagonismo dos interesses sociais (Iamamoto, in Iamamoto e Carvalho, 1982).

Como a sociedade é atravessada por projetos sociais distintos - projeto de classes para a sociedade - tem-se um terreno sócio-histórico aberto à construção 
de projetos profissionais também diversos, indissociáveis dos projetos mais amplos para a sociedade. É essa presença de forças sociais e políticas reais - e não mera ilusão - que permite à categoria profissional estabelecer estratégias político-profissionais no sentido de reforçar interesses das classes subalternas, alvo prioritário das ações profissionais.

O exercício da profissão exige um sujeito profissional que tenha competência para propor e negociar com a instituição os seus projetos, para defender o seu campo de trabalho, suas qualificações e atribuições profissionais. Requer ir além das rotinas institucionais para buscar apreender, no movimento da realidade e na aproximação as forças vivas de nosso tempo, tendências e possibilidades aí presentes passíveis de serem apropriadas pelo profissional e transformadas em projetos de trabalho profissional.

Os(as) assistentes sociais têm nas múltiplas expressões da "questão social", tais como vividas pelos indivíduos sociais, a "matéria" sobre a qual incide o trabalho profissional. Ela é moldada tanto pelas políticas públicas quanto pelas lutas sociais cotidianas de diferentes segmentos subalternos que vêm à cena púbica para expressar interesses e buscar respostas às suas necessidades.

O Estado, nos diversos níveis da federação, é hoje o maior empregador dos assistentes sociais, e a atuação na órbita das políticas públicas um espaço profissional privilegiado desse profissional. Existe uma necessária autonomia entre o trabalho profissional na política pública e a política pública. Profissão não se confunde com política pública de governo ou de Estado e nem o Serviço Social se confunde com assistência social, ainda que esta possa ser uma das mediações persistentes da justificativa histórica da existência da profissão. Assim, seus agentes não são meros operacionalizadores de políticas emanadas do Estado - um braço operacional do moderno príncipe - , ainda que a política pública - $\mathrm{e}$ particularmente a seguridade social — seja uma mediação determinante no exercício da profissão no mercado de trabalho como uma das respostas institucionalizadas à "questão social". Essas afirmativas têm consequências para tratar o tema proposto, pois a profissão não se confunde com a responsabilidade do governo e de Estado, constitucionalmente responsáveis pela formulação, gestão, financiamento de políticas e programas sociais, ainda que a atuação nesse campo seja uma de nossas competências profissionais, resguardadas pela Lei de Regulamentação da Profissão, de 1993. Certamente existem tensões entre projetos profissionais e políticas governamentais e nítidas disputas teóricas e políticas no direcionamento do Serviço Social brasileiro. 
No nível da formação acadêmico-profissional existem, em agosto de 2011, 358 cursos de graduação autorizados pelo $\mathrm{MEC}$, dos quais dezoito de ensino a distância (EAD) que ofertam, no mesmo ano, 68.742 vagas. Na modalidade presencial os 340 cursos ofertam, em 2011, 39.290 vagas, segundo as Sinopses Estatísticas do MEC, totalizadas por Larissa Dahmer, em 2013. ${ }^{1}$ As matrículas em cursos de Serviço Social assim se distribuem, em 2011: na modalidade EAD 80.650 matrículas e na modalidade presencial 72.019 matrículas.

A pós-graduação stricto sensu na área de Serviço Social encontra-se consolidada com 34 programas: 34 cursos de mestrado e 16 de doutorado, todos de caráter acadêmico, com ênfase em Serviço Social, Políticas Públicas e Políticas Sociais. ${ }^{2}$

Segundo a atual direção da Abepss (gestão 2012-14), a prioridade para a entidade no nível da formação graduada é a regulamentação do Plano Nacional de Estágio no Conselho Nacional de Educação. Já no nível da pesquisa e da pós-graduação, as prioridades voltam-se para a revisão das linhas de pesquisa da área no $\mathrm{CNPq}$, para o debate coletivo sobre a orientação acadêmica dos programas de pós-graduação e para o impulso aos intercâmbios internacionais na área de Serviço Social. ${ }^{3}$

O contingente de assistentes sociais brasileiros é o segundo no cenário mundial, com 135 mil profissionais ativos, conforme dados do Conselho Federal de Serviço Social (CFESS), apenas superado pelos EUA, num total de 750 mil assistentes sociais no mundo, conforme a International Federation of Social Workers (IFSW). ${ }^{4}$

O debate no Serviço Social brasileiro tem sido polarizado por um duplo e contraditório movimento: o mais representativo impulsiona o processo de ruptura teórica e política com o lastro conservador de suas origens. Em sinal contrário, verifica-se o revigoramento de uma reação (neo)conservadora aberta e/ou disfarçada em aparências que a dissimulam, como já indicou Netto (1996), apoiada no lastro da produção pós-moderna e sua negação da sociedade de classes. Mas, nas três últimas décadas, construímos coletivamente um patrimônio sociopolítico e

1. Os dados foram gentilmente cedidos pela dra. Larissa Dahmer, a quem registramos nossos agradecimentos.

2. Disponível em: <http://conteudoweb.capes.gov.br/conteudoweb/ProjetoRelacaoCursosServlet?acao $=$ pesquisarArea\&identificador=32\#>. Acesso em: 20 ago. 2014.

3. Informações prestadas à autora pela presidente da Abepss, prof. dra. Maria Regina de Ávila Moreira, no decurso do XIV Congresso Brasileiro de Assistentes Sociais, realizado em Águas de Lindoia (SP), em 2013, a quem agradecemos.

4. Disponível em: <http://ifsw.org/what-we-do/>. Acesso em: 6 set. 2013. 
profissional que atribui uma face peculiar ao Serviço Social brasileiro no cenário da América Latina e Caribe e no circuito mundial do Serviço Social. O núcleo desse patrimônio é compreensão da história a partir das classes sociais e suas lutas, da centralidade do trabalho e dos trabalhadores. Ele foi alimentado teoricamente pela tradição marxista - no diálogo com outras matrizes analíticas - e politicamente pela aproximação das forças vivas que movem a história; as lutas e movimentos sociais.

Dentre as conquistas desse patrimônio coletivo merece destaque:

- Na contramão do mar de individualismo e insensibilidade ante aos dilemas da coletividade, os assistentes sociais preservaram sua capacidade de indignação diante das desigualdades e injustiças sociais, mantendo viva a esperança em tempos mais humanos.

- No campo do exercício profissional tem sido impulsionada a busca permanente de aperfeiçoamento, a inquietação criadora e o compromisso com a qualidade dos serviços prestados, que busca fina sintonia com as necessidades dos sujeitos.

- Os assistentes sociais vêm construindo na sua prática cotidiana uma nova imagem social de profissão relacionada aos direitos, apoiando a participação qualificada dos sujeitos sociais em defesa de suas necessidades e direitos.

- Avançou-se no autorreconhecimento do(a) assistente social como trabalhador assalariado, partícipe do trabalho social coletivo, mediante uma atitude crítica e ofensiva na defesa das condições de trabalho e da qualidade dos atendimentos. É ilustrativa a mobilização pela aprovação da Lei n. 2.317/2010, que trata da redução da carga horária semanal de trabalho do assistente social para 30 horas sem redução de salário (CFESS, 2011).

- Esforços foram empreendidos para a qualificação das competências e atribuições do(a) assistente social resguardadas pela Lei da Regulamentação da Profissão, de 1993, nos segmentos mais representativos do mercado de trabalho: na assistência, na saúde, na educação, na área sociojurídica, o que requer permanente aperfeiçoamento e atualização (CFESS, 2010, 2013a, 2023b, 2012a, 2012b). Todavia, é necessário atribuir maior visibilidade às experiências inovadoras de trabalho na perspectiva do projeto profissional coletivamente construído.

- A pauta temática da pesquisa indica uma profissão com profunda vocação histórica e com uma inquietante agenda de debates que denota fecunda 
interlocução do Serviço Social com o movimento da sociedade. O Serviço Social no Brasil é hoje reconhecido como área de conhecimento no campo de Ciências Sociais aplicadas por parte das agências públicas oficiais de fomento à pesquisa e à inovação tecnológica, conquista pioneira no Serviço Social latino-americano.

\section{Diretrizes curriculares e projeto profissional: reservas de forças e resistência política}

As atuais diretrizes curriculares — propostas inicialmente pela Abess em 1996 e revistas em 1999 —, têm no currículo mínimo aprovado pelo MEC em 1982, seu antecedente mais importante. Este foi proposto pela Abess em 1979, em pleno período ditatorial, incorporando alguns avanços do movimento de reconceituação latino-americano. O currículo mínimo expressa um processo de transição, parte da resistência acadêmica e política tanto à ditadura militar implantada no país (196485) quanto ao Social Work, em sua difundida trilogia, composta por Serviço Social de caso, de grupo e de comunidade.

No currículo aprovado pelo MEC em 1982, a matriz do ensino do Serviço Social centra-se nas ementas voltadas para História do Serviço Social, Teoria do Serviço Social e Metodologia do Serviço Social além do estágio supervisionado -, o que representou um enorme desafio teórico e de pesquisa no sentido de dar sustentação a estes conteúdos. É desse período a introdução da política social no universo da formação acadêmica, quando se vincula o exercício profissional às políticas sociais públicas, sendo as relações entre o Estado e a sociedade de classes decisivas para decifrar o significado social da profissão.

Remonta aos anos 1980, a criação do primeiro curso de doutorado em Serviço Social e o estímulo sistemático à pesquisa nessa área. Surge, em 1983, o I Encontro Nacional de Pesquisa em Serviço Social - depois Encontro Nacional de Pesquisadores em Serviço Social). Em 1987, é criado o Centro de Documentação e Pesquisa em Política e Serviço Social (Cedepss), organismo acadêmico da Abess. ${ }^{5}$

5. A implementação do currículo de 1982 pela Abess foi acompanhada de uma pesquisa nacional sobre a formação profissional (Carvalho et al., 1984), além de pesquisas locais que apoiaram a implantação de currículos plenos, como foi a experiência exemplar da PUC-SP (Yazbek, 1984). 
Tem-se ainda a conquista do reconhecimento acadêmico do Serviço Social como área de conhecimento no CNPq, em 1984, passando, em 1986, a compor o Comitê de Psicologia e Serviço Social (Baptista e Rodrigues, 1992, p. 127) com forte impulso de parte de docentes da PUC-SP.

O Serviço Social beneficia-se de amplo movimento de lutas pela democratização da sociedade e do Estado no país, com forte presença das lutas operárias que impulsionaram a crise da ditadura militar do período 1964-84. No contexto de ascensão dos movimentos sociais, das lutas em torno da elaboração e aprovação da Carta Constitucional de 1988 e da defesa do Estado de direito, a categoria foi sendo socialmente questionada pela prática política de diferentes segmentos da sociedade civil com o avanço das lutas democráticas.Tal processo condiciona, fundamentalmente, o horizonte de preocupações emergentes no âmbito do Serviço Social no país e passa a exigir novas respostas profissionais, o que derivou em significativas alterações nos campos do ensino, da pesquisa e da organização político-corporativa dos assistentes sociais. Revigora-se uma ampla e fecunda organização da categoria em suas bases sindicais, acadêmicas e profissionais, que vão dar sustentação ao projeto O Serviço Social no Brasil, uma experiência inovadora no cenário profissional mundial.

A década de 1980 é um marco no debate sobre os fundamentos do Serviço Social no Brasil inspirado na teoria social crítica, que norteia um projeto acadêmico-profissional do Serviço Social brasileiro expresso na renovação da legislação profissional (1993), na normatização ética (1993) e nas diretrizes curriculares nacionais (Abess, 1996; MEC-Sesu, Ceess, 1999). Este patrimônio sociopolítico e profissional vem atribuindo uma face peculiar ao Serviço Social brasileiro na América Latina e Caribe, bem como no circuito mundial do Serviço Social. Seu núcleo central é a compreensão da história a partir das classes sociais e suas lutas, o reconhecimento da centralidade do trabalho e dos trabalhadores. Ele foi alimentado teoricamente pela tradição marxista — no diálogo com outras matrizes analíticas - e politicamente pela aproximação às forças vivas que movem a história: as lutas e os movimentos sociais.

As diretrizes curriculares para o curso de Serviço Social são fruto de amplo e diversificado debate acadêmico em oficinas locais, regionais e nacionais. Eles permitiram dar forma à proposta do "currículo mínimo" em 1996 (Abess-Cedepss, 1996, 1997a, 1997b), que também contou com o protagonismo de parcela expressiva da intelectualidade da área de Serviço Social na assessoria à então ABESS. 
Nesse lapso temporal, essa entidade, então sob a direção da profa. Marieta Koike, abriu simultaneamente espaços no MEC-Sesu para a criação da Comissão de Especialistas de Ensino em Serviço Social, responsável, entre outras funções, por apreciar e encaminhar ao Conselho Nacional de Educação (CNE) as diretrizes curriculares da área, expressando uma articulação política importante para a preservação da proposta original da Abess.

A proposta de currículo mínimo foi atropelada pelo processo de contrarreforma do ensino superior, preconizado pelos organismos multilaterais. Os currículos mínimos são substituídos por diretrizes curriculares mais flexíveis, exigindo a definição do perfil do bacharel em Serviço Social, a substituição de ementas das disciplinas por tópicos de estudos com caráter não obrigatório, a definição de competências e habilidades técnico-operativas. Diante de tais exigências, a Comissão de Especialistas convoca um grupo de assessores que havia participado do processo de elaboração das diretrizes para a revisão final do texto. ${ }^{6}$ Recusando a adequação da formação às competências definidas pelo mercado, recorre-se às competências e atribuições previstas na Lei da Regulamentação da Profissão e em preceitos do Código de Ética do Assistente Social, documentos legitimados e constitutivos da materialização jurídica do projeto profissional. Tais alterações são submetidas à apreciação de representantes das entidades nacionais - CFESS, Abess e Enesso - e, posteriormente, apresentadas e aprovados na assembleia ordinária da Abepss. ${ }^{7}$

Já o texto legal das diretrizes curriculares, homologadas em 4/7/2001 pelo Ministério da Educação e do Desporto (MEC-Sesu, 1999), sofre forte descaracterização no que se refere à direção social da formação profissional, aos conhecimentos e habilidades considerados essenciais ao desempenho do assistente social. Assim, por exemplo, no perfil do bacharel em Serviço Social constava "profissional

6. Agregam-se à Comissão de Especialistas de Ensino para revisão das diretrizes curriculares, em reunião realizada na PUC-SP, os seguintes assessores: Marina Abreu, José Paulo Netto, Maria Rosângela Batistoni e Marieta Koike.

7. A apresentação, na assembleia da Abepss, das Diretrizes Curriculares, encaminhadas ao CNE, foi efetuada por Maria Bernadete Martins Pinto Rodrigo, Marilda Villela Iamamoto e Mariângela Belfiore Wanderley, então componentes da Comissão de Especialistas de Ensino em Serviço Social. Isto ocorre quando a profa. dra. Ivanete Boschetti assume a direção da entidade. Assim não existiram distintas propostas de diretrizes, a da Abepss e a da Comissão de Especialistas, mas uma única proposta submetida a um processo de aperfeiçoamento do texto original de currículo mínimo para viabilizar seu encaminhamento ao Conselho Nacional de Educação - CNE, submetida à apreciação e aprovação pela assembleia da entidade, sua maior instância deliberativa. Cf. MEC-Sesu, 1999. 
comprometido com os valores e princípios norteadores do Código de Ética do Assistente Social", o que foi retirado e substituído por "utilização dos recursos da informática". Na definição das competências e habilidades, é suprimido do texto legal o direcionamento teórico-metodológico e histórico para a análise da sociedade brasileira: apreensão crítica dos processos sociais na sua totalidade; análise do movimento histórico da sociedade brasileira, apreendendo as particularidades do desenvolvimento do capitalismo no país (MEC-Sesu/Coness, 1999). Também os tópicos de estudos foram totalmente banidos do texto oficial em todas as especialidades. Eles consubstanciavam o detalhamento dos conteúdos curriculares anunciados nos três núcleos de fundamentação que compõem a organização curricular: núcleo de fundamentos teórico-metodológicos da vida social; núcleo de formação sócio-histórica da sociedade brasileira e núcleo de fundamentos do trabalho profissional. Este corte significa, na prática, a dificuldade de garantir um conteúdo básico comum à formação profissional no país. ${ }^{8} \mathrm{O}$ conteúdo da formação passa a ser submetido à livre-iniciativa das unidades de ensino condizente com os ditames do mercado, desde que preservados os referidos núcleos.

A resistência política à feição legal das diretrizes tem sido viabilizada politicamente pela representatividade da proposta da Abepss, que passou a ser observada pelos docentes e consultores nas avaliações oficiais dos cursos de graduação em Serviço Social.

As diretrizes curriculares para o curso de Serviço Social, propostas pela Abess/ Cedepss, reconhecem o Serviço Social como uma especialização do trabalho da sociedade, inscrita na divisão social e técnica do trabalho social, o que supõe afirmar o primado do trabalho na constituição dos indivíduos sociais.

Esse modo de vida implica contradições básicas: por um lado, a igualdade jurídica dos cidadãos livres é inseparável da desigualdade econômica derivada do caráter cada vez mais social da produção, contraposta à apropriação privada do trabalho alheio. Por outro lado, ao crescimento do capital corresponde a crescente pauperização relativa do trabalhador. Esta é a lei geral da produção capitalista, que se encontra na gênese da "questão social" nessa sociedade. São essas forças contraditórias, inscritas na própria dinâmica dos processos sociais, que criam as bases reais para a renovação do estatuto da profissão conjugadas à intencionalidade dos seus agentes.

8. Cf. também sobre o tema Ortiz (2013) e Abepss (2008). 
O significado sócio-histórico e ideopolítico do Serviço Social inscreve-se no conjunto das práticas sociais acionado pelas classes e mediadas pelo Estado em face das "sequelas" da questão social. A particularidade do Serviço Social na divisão social e técnica do trabalho coletivo encontra-se "organicamente vinculada às configurações estruturais e conjunturais da 'questão social'e às formas históricas de seu enfrentamento, que são permeadas pela ação dos trabalhadores, do capital e do Estado. (Abess/Cedepss, 1996, p. 154)

A “questão social" é indissociável da sociabilidade capitalista (Netto, 2001; Iamamoto, 2007) e envolve uma arena de lutas políticas e culturais contra as desigualdades socialmente produzidas. Suas expressões condensam múltiplas desigualdades mediadas por disparidades nas relações de gênero, características étnico-raciais e formações regionais, colocando em causa amplos segmentos da sociedade civil no acesso aos bens da civilização. Dispondo de uma dimensão estrutural - enraizada na produção social contraposta à apropriação privada do trabalho - , a "questão social" atinge visceralmente a vida dos sujeitos numa luta aberta e surda pela cidadania (Ianni, 1992), no embate pelo respeito aos direitos civis, sociais e politicos e aos direitos humanos. Esse processo é denso de conformismos e rebeldias, expressando a consciência e a luta que acumulam forças para o reconhecimento das necessidades de cada um e de todos os indivíduos sociais. É na tensão entre produção da desigualdade, da rebeldia e do conformismo que trabalham os assistentes sociais, situados nesse terreno movido por interesses sociais distintos, aos quais não é possível abstrair - ou deles fugir - porque tecem a trama da vida em sociedade. Foram as lutas sociais que romperam o domínio privado nas relações entre capital e trabalho, extrapolando a "questão social" para a esfera pública, exigindo a interferência do Estado no reconhecimento e a legalização de direitos e deveres dos sujeitos sociais envolvidos, consubstanciados nas políticas e serviços sociais, mediações fundamentais para o trabalho do assistente social (Iamamoto, 2007).

A atuação dos assistentes sociais dá-se no âmbito das relações entre as classes e destas com o Estado no enfrentamento das múltiplas expressões da "questão social", sendo a política social uma mediação fundamental do exercício profissional voltado para a sua formulação, gestão avaliação e financiamento, assim como para a assessoria aos movimentos sociais. Desenvolvemos uma ação educativa na prestação de serviços sociais, viabilizando o acesso aos direitos e aos meios de exercê-los e contribuindo para que necessidades e interesses dos sujeitos de direitos 
adquiram visibilidade na cena pública e possam ser reconhecidos. Afirmamos o compromisso com os direitos e interesses dos usuários, na defesa da qualidade dos serviços sociais.

As diretrizes curriculares reafirmam a "questão social" como base de fundação sócio-histórica da profissão, salientando as respostas do Estado, do empresariado $e$ as ações das classes trabalhadoras no processo de constituição, afirmação e ampliação dos direitos sociais (Abess/Cedepss, 1997a e 1997b).

Decifrar as novas mediações por meio das quais se expressa a "questão social hoje é de fundamental importância para o Serviço Social em uma dupla perspectiva: para apreender as várias expressões que assumem, na atualidade, as desigualdades sociais — sua produção e reprodução ampliada — e para projetar formas de resistência e de defesa da vida e dos direitos, que apontam para novas formas de sociabilidade.

As diretrizes curriculares, ${ }^{9}$ com base nesses fundamentos, estabelecem como perfil do bacharel em Serviço Social:

"profissional que atua nas expressões da questão social, formulando e efetivando propostas para seu enfrentamento por meio de políticas sociais públicas, empresariais, de organizações da sociedade civil e movimentos sociais; profissional dotado de for-

9. A formação em Serviço Social propõe-se a: "viabilizar a capacitação teórico-metodológica e ético-política como requisito fundamental para o exercício de atividades técnico-operativas, com vistas à: apreensão crítica dos processos sociais numa perspectiva de totalidade e do movimento histórico da sociedade brasileira; possibilitar a compreensão do significado social da profissão e de seu desenvolvimento sócio-histórico, nos cenários internacional e nacional, desvelando as possibilidades de ação contidas na realidade; e identificar demandas presentes na sociedade, visando formular respostas profissionais para o enfrentamento da questão social, considerando as novas articulações entre o público e o privado".

Dentre os principios norteadores da formação acadêmico-profissional tem-se:

1. rigoroso tratamento teórico, histórico e metodológico da realidade social e do Serviço Social que possibilitem a compreensão dos problemas e desafios com os quais o profissional se defronta no universo da produção e reprodução da vida social;

2. adoção de uma teoria social crítica que possibilite a apreensão da totalidade social em suas dimensões de universalidade, particularidade e singularidade; debate entre tendências teóricas presentes nas ciências humanas e sociais;

3. integração entre as dimensões de formação e investigação, a interdisciplinaridade e indissociabilidade entre ensino, pesquisa e extensão;

4. ética como principio transversal à formação e estreita articulação entre supervisão acadêmica e profissional na atividade de estágio. 
mação intelectual e cultural generalista crítica, competente em sua área de desempenho, com capacidade de inserção criativa e propositiva no conjunto das relações sociais e no mercado de trabalho; profissional comprometido com os valores e princípios norteadores do Código de Ética do Assistente Social” (Diretrizes Curriculares, 1999).

\section{Algumas inovações das diretrizes curriculares}

O conteúdo da formação está sustentado em três núcleos temáticos, o que representa uma inovação na maneira de pensar a formação acadêmica. São eles: a) Núcleo dos fundamentos teórico-metodológicos e ético-políticos da vida social; b) Núcleo dos fundamentos da formação sócio-histórica da sociedade brasileira e do significado do Serviço Social no seu âmbito; c) Núcleo dos fundamentos do trabalho profissional, abrangendo elementos constitutivos do Serviço Social enquanto especialização do trabalho: trajetória histórica, teórica, metodológica e técnica, os componentes éticos que envolvem o exercício profissional, a pesquisa, o planejamento e a administração em Serviço Social e o estágio supervisionado.

Tais núcleos, ainda que por vezes tratados como uma tricotomia e independentes uns dos outros, foram concebidos enquanto diferentes níveis de abstração necessários, complementares e interdependentes para decifrar o Serviço Social inscrito na dinâmica societária. Abrangem, respectivamente, dimensões teórico-sistemáticas, particularidades históricas (continentais, nacionais, regionais elou locais), que determinam o trabalho profissional e nele se condensam, enquanto dimensões indispensáveis à sua análise.

Outra inovação das diretrizes refere-se à centralidade atribuída à prática profissional na formação acadêmica, concebida sob a ótica teórica do trabalho. Esta não representa mera mudança terminológica, mas tem profundas implicações analíticas. Busca-se adensar o campo de determinações e relações para a apreensão da profissão em seu processamento: acionada pelos sujeitos profissionais na relação com os segmentos de classe — em suas bases institucionais públicas e privadas que contratam o(a) assistente social; e aqueles a quem se dirige prioritariamente o trabalho profissional (segmentos das classes trabalhadoras com recortes de gênero, etnia, geração, renda etc.). No processo de construção das diretrizes curriculares, o núcleo teórico estruturante dessa análise foi a centralidade do trabalho na conformação das atividades desse segmento especial de trabalhadores assalariados: os assistentes sociais, o que tem sido fonte de provocativas polêmicas. 
A conjunção entre trabalho assalariado e projeto profissional permite atribuir visibilidade no universo da profissão ao clássico dilema entre estrutura e ação do sujeito, entre necessidade e liberdade, considerando os agentes profissionais em sua condição de resultantes e sujeitos da história. O projeto profissional reconhece o assistente social como um ser prático-social dotado de liberdade, capaz de projetar coletivamente seu trabalho e buscar sua implementação por meio de sua atividade. Esta condição é tensionada pelo trabalho assalariado submetido ao Estado e ao poder patronal, que restringe a relativa autonomia do assistente social e submete nossa atividade aos dilemas da alienação. As diferentes condições de trabalho redimensionam socialmente o significado das projeções profissionais que sofrem interferência tanto das lutas sociais quanto das condições de trabalho, da autoridade e dos interesses dos contratantes. Como nos sugere Amaral e César (2009, p. 415), estão aí colocados limites - dados pelas condições objetivas de trabalho - e, simultaneamente, as possibilidades de ação profissional apoiadas em nossa capacidade de compreender a realidade, propor alternativas e negociar, junto ao poder contratante, o atendimento às necessidades fundamentais à reprodução da força de trabalho. Tais determinações são indissociáveis da mercantilização dessa força de trabalho. Assim, essa ótica de análise requer articular: a) a qualidade desse trabalho, sua diferencialidade dos demais tipos de trabalho, expressa em seu caráter de atividade útil ou trabalho concreto, o que requer respostas técnicas e políticas de parte dos profissionais especializados; b) com sua identidade com o trabalho social médio, enquanto trabalho abstrato, fração do trabalho social total. Esta dupla dimensão do trabalho do assistente social o identifica com o conjunto da classe trabalhadora, suas formas de organização e de lutas.

A compreensão acerca dos fundamentos do Serviço Social é informada pela perspectiva da totalidade histórica. Parte do pressuposto de que a história da sociedade é o terreno privilegiado para apreensão das particularidades do Serviço Social: do seu modo de atuar e de pensar incorporados ao longo de seu desenvolvimento. Sendo a profissão um produto sócio-histórico, adquire sentido e inteligibilidade na dinâmica societária da qual é parte e expressão. Decifrar essa especialização do trabalho supõe, nesse sentido, elucidar os processos sociais que geram a sua necessidade social, o significado de suas ações no campo das relações de poder econômico e político - das relações entre as classes e destas com o Estado -, assim como a inscrição do Serviço Social no debate teórico e cultural de seu tempo. Portanto, situar o Serviço Social na história é distinto de uma história do Serviço Social reduzida aos muros da profissão, que tende a erigir o discurso dos 
profissionais como achados conclusivos da pesquisa. Esses, ao contrário, são materiais a serem submetidos ao crivo da crítica teórico-metodológica, redimensionando o seu significado no jogo das forças sociais.

Essa concepção é inspirada em uma tradição cultural que, ao privilegiar a história, reconhece não serem as categorias teóricas, com as quais se procede a análise, fruto de uma formulação autônoma e aleatória do processo de pensar. Ao contrário, as categorias teóricas são entendidas como expressões, na esfera da razão, de modos de ser, determinações da existência, dadas na realidade efetiva (Marx, 1974, p. 27). Estabelece-se, pois, como quesito fundamental a indissociável articulação entre conhecimento e história, entre teoria e realidade (prática social), em que o método - não se reduzindo a pautas de procedimentos para o conhecer elou o agir - expressa-se na lógica que organiza o processo mesmo do conhecimento. Requer que os fenômenos e processos sociais sejam retraduzidos na esfera do pensamento, que procura aprendê-los nas suas múltiplas relações e determinações, isto é, em seus processos de constituição e de transformação pleno de contradições e mediações (em sua totalidade). Mas desvendar a profissão é, também, elucidar a herança cultural a partir da qual se constrói a explicação sobre o seu fazer, expressa no discurso profissional.

O Serviço Social não surge como parte da divisão do trabalho entre as ciências, ainda que produza investigações que adensam o acervo das ciências sociais e humanas, hoje inscrito no circuito oficial das ciências sociais aplicadas. O Serviço Social afirma-se como uma profissão, que vem respaldando seu exercício, sistematizações, saberes e a produção científica acumulada por seus pesquisadores no acervo intelectual e cultural herdado fundamentalmente do pensamento social na modernidade, sofrendo, hoje, os influxos da crítica pós-moderna.

Em seus primórdios, o Serviço Social estabeleceu uma interlocução privilegiada com o pensamento social católico e com o pensamento conservador europeu, tendo se secularizado em estreita aproximação com as concepções estrutural-funcionalistas difundidas nas ciências sociais e humanas norte-americanas, além da incorporação de rudimentos da psicanálise. A aproximação teórica da profissão ao universo da tradição marxista ocorre tardiamente, a partir de meados dos anos 1960 na América Latina, no bojo do conhecido "movimento de reconceituação do Serviço Social". Instaura-se, a partir de então, uma tendência ao debate plural no campo da ideias no meio acadêmico do Serviço Social. Assim sendo, é impossível decifrar a profissão independente do diálogo crítico com o acervo intelectual, que 
vem alimentando, historicamente, a cultura profissional, estabelecendo distintos parâmetros de qualificação da profissão e de sua função na sociedade.

As dimensões históricas, teóricas e metodológicas passam a ser tratadas de forma indissociáveis e complementares nessa concepção de fundamentos do Serviço Social. Estabelece-se uma interlocução simultânea entre a história da sociedade e a história da cultura de uma época para elucidar o Serviço Social. Em outros termos, busca-se decifrar a história e, simultaneamente, o pensamento que pensa a história questionando "o real e o pensado, tanto os pontos de vista dos membros dos grupos e classes compreendidos na pesquisa quanto as interpretações elaboradas sobre eles" (Ianni, 2004, p. 317), como nos sugerem Octavio Ianni e Florestan Fernandes. Isto implica pesquisa histórica e diálogo crítico teórico e metodológico com o processo de construção do conhecimento, reconhecendo o caráter heurístico de conjunturas de inflexão e crise na história do país, assim como as influências internacionais que incidem na produção do conhecimento.

Essa densa linha temática de investigação representa um manancial de descobertas a serem processadas e elaboradas. Poder-se-ia afirmar que a história do Serviço Social, especialmente no Brasil e na América Latina, ainda é um fecundo campo aberto à pesquisa científica. Em outros termos, o Serviço Social rompeu com a endogenia na análise da profissão, defrontou-se com os processos sociais macroscópicos que circunscrevem seu desempenho, sendo necessária a "viagem de retorno à profissão" para reconstruí-la nas suas múltiplas relações e determinações como "concreto pensado". Essa concepção sobre os fundamentos do trabalho do assistente social é radicalmente histórica e aberta a um vivo acompanhamento crítico do universo cultural e político contemporâneo. Ela impulsiona uma formação culta e universalista, capaz de propiciar uma leitura do exercício profissional que apreenda suas características nas múltiplas determinações e relações em que se constitui. E está voltada para sedimentar uma teleologia historicamente fundada em valores e princípios éticos que norteiam a formação de competências e habilidades necessárias à sua operacionalização.

Instaura-se um debate, expresso na literatura, entre distintas visões do Serviço Social, inclusive no interior do campo progressista. No universo dos pesquisadores que reivindicam um vínculo com a tradição marxista, afloram maneiras de pensar e explicar a profissão sob diferentes matizes, sob a inspiração de Marx, Gramsci, Lukács e influxos hegelianos. A ótica de leitura desses clássicos — assim como a leitura que é feita de suas obras — direciona angulações privilegiadas na 
análise da profissão e de seu exercício: a ênfase no trabalho, na práxis e na organização da cultura, na ideologia e na formação da consciência, que merecem debate.

O debate quanto aos fundamentos do Serviço Social, nas três últimas décadas, centrou-se nos seguintes eixos temáticos (sem nenhuma pretensão de esgotar o tema): (a) o resgate da historicidade da profissão, seja na reconstituição de sua trajetória na formação histórica da sociedade brasileira, seja na explicitação das particularidades históricas de sua inserção da divisão social e técnica do trabalho; (b) a crítica teórico-metodológica tanto do conservadorismo quanto da vulgarização marxista, introduzindo a polêmica em torno das relações entre história, teoria e método no Serviço Social, que hoje vem recebendo influxos da chamada crise dos paradigmas e do pensamento pós-moderno (Netto, 1996); (c) a ênfase na política social pública, no campo das relações entre o Estado e a sociedade civil, com especial atenção para a seguridade social e, nela, para a política de assistência social e de saúde; (d) o debate teórico e político sobre a questão social: interpretações e expressões no país; (e) o debate sobre a ética e o projeto profissional; (f) o debate sobre a reestruturação produtiva e a centralidade do trabalho nas alterações no mercado de trabalho, nas formas de consumo da força de trabalho e no perfil dos trabalhadores, considerando suas incidências no trabalho do assistente social; (g) o debate sobre o exercício profissional: trabalho, ideologia ou práxis?

\section{Determinantes sócio-históricos e acadêmicos do processo de implantação das diretrizes curriculares}

A implantação das diretrizes curriculares conviveu com profunda transformação no processo de acumulação para fazer frente à tendência de baixo crescimento da economia mundial ou a uma "onda longa depressiva", nos termos de Mandel (1985), após os trinta anos gloriosos de crescimento desde o pós-guerra.

A educação, pensada como uma política social pública, dispõe de um caráter contraditório ao atender, simultaneamente, interesses de acumulação do capital e do conjunto dos trabalhadores no processo de criação e socialização de conhecimentos. A política de educação superior encontra-se sujeita às forças contraditórias que nela incidem: tanto as forças que impulsionam a financeirização da vida social — e dela se beneficiam - para desenvolver as forças produtivas sociais do trabalho e alimentar superlucros dos monopólios no mercado mundial quanto dos interesses da 
maioria dos trabalhadores e do conjunto das classes subalternas na busca de seus direitos e na luta por seus interesses coletivos. Ambos os feixes de interesses têm no Ensino Superior um nicho central na formação de força de trabalho altamente qualificada, da produção da ciência, da tecnologia e da inovação. Ele se torna, assim, uma arena de disputas em torno de projetos de formação universitária, afirmando-se também a possibilidade de propostas de resistência às orientações dominantes.

A construção coletiva de proposta de formação acadêmica no Serviço Social norteia-se pela defesa da universidade pública, gratuita e de qualidade, direcionada aos interesses da coletividade e enraizada na realidade regional e nacional; a universidade que cultiva razão crítica e o compromisso com valores universais, coerente com sua função pública, não limitada e submetida a interesses particulares exclusivos de determinadas classes ou frações de classes; uma instituição a serviço da coletividade, que incorpore os dilemas regionais e nacionais como matéria da vida acadêmica, participando da construção de respostas aos mesmos no âmbito de suas atribuições.

Sabe-se que a tendência predominante tem sido imprimir uma lógica mercantil e empresarial à universidade, estimulando a sua privatização: o que Chaui $(1995,1999)$ denomina de "universidade operacional" ou "universidade de resultados e serviços", condizente com as recomendações dos organismos multilaterais. O propósito é compatibilizar o ensino superior com financeirização da economia, fazendo com que as descobertas científicas e o seu emprego na produção se tornem meios de obtenção de lucros excedentes, o que justifica a orientação de submeter a universidade aos interesses empresariais, explícita nas políticas de ciência, tecnologia e inovação, em tempos de mundialização do capital presidida pelas finanças.

A partir da década de 1990, os organismos multilaterais - Unesco, Banco Mundial, OCDE e a União Europeia - buscam um novo perfil do ensino superior centrado na formação por competências. ${ }^{10} \mathrm{~A}$ premissa é que os avanços da ciência e da tecnologia na sociedade contemporânea têm levado à "sociedade do conhecimento e da informação" num mundo "globalizado" e com vistas ao crescimento econômico no século XXI. O Banco Mundial (2003) salienta o papel do conhecimento como principal motor para o desenvolvimento e a necessidade de favorecer os compromissos das instituições de ensino superior com a inovação para melhor responder "às necessidades da economia e do mercado".

10. Sobre o tema, ver a tese de doutorado de Werner, 2010. 
A proposta do ensino superior por competência substitui o foco no conhecimento com valor maior em favor das capacidades instrumentais. A tendência é deslocar o centro de interesse dos conteúdos teóricos para outros de caráter instrumental, centrados na prática e no sistema produtivo, sensíveis às exigências do mercado. Para obter "maior eficiência com o menor gasto público" preconiza-se a avaliação por competências: comunicação verbal e escrita, trabalho em equipe, criatividade, capacidade de pensamento visionário, recursividade e capacidade de ajuste a mudanças (Banco Mundial, 2003).

Apesar da polissemia da noção de competência, ${ }^{11}$ ela parte da crítica da compartimentalização disciplinar do conhecimento para ressaltar a experiência vivida pelo sujeito como referência importante de aprendizagem. Mas ela está associada às novas concepções de trabalho baseadas na flexibilidade e reconversão permanente. A noção surge do questionamento ao conceito de qualificação e do processo de formação profissional especialmente técnica (Fleury e Fleury, 2001; Ramos; 2001, 2002 e 2008). A competência apresenta-se como inteligência prática, que se apoia sobre conhecimentos adquiridos (saberes, capacidades, informações etc.), dotando-os de maior eficácia. Segundo o Parlamento europeu e o Conselho da União Europeia, as competências básicas são uma combinação de conhecimentos, capacidades e atitudes, que todas as pessoas necessitam para sua realização pessoal. É também definida como uma unidade configurada pelo saber, pelo saber-fazer e pelo saber ser (Ramos, 2001, p. 2), envolvendo experiências vividas e a própria subjetividade. ${ }^{12}$

11. Em 1999, ministros de Educação de 29 países se encontraram em Bolonha (Itália), quando foi firmada a Declaração de Bolonha, também assinada pela Comissão Europeia, Conselho da Europa, associações universitárias, reitores e estudantes. Ela favorece a mobilidade e a competitividade no espaço europeu. São seus objetivos: a) implantação de um sistema de titulações comparável, criando o Suplemento Europeu de Títulos para proporcionar o emprego e a competitividade; b) estruturar o ensino de dois ciclos fundamentais: graduação (bacharelato e licenciatura), realizado em um período de três anos, e pós-graduação (mestrado e doutorado); c) estabelecer um sistema de créditos comum - ETCS (Europeu Credit Transfer System), como meio de proporcionar ampla mobilidade estudantil. Os créditos também poderão ser obtidos fora das IES, incluindo a experiência adquirida, desde que reconhecida por universidades; d) promover a cooperação europeia para garantir a qualidade mediante critérios e metodologias comparáveis (interativas, construtivas, interdisciplinares, centradas no aluno), com ênfase no conhecimento do como fazer.

12. As competências podem ser classificadas em básicas, transversais e especificas: a) Competências básicas: comunicação em língua materna; comunicação em língua estrangeira; competência matemática e em ciências e tecnologias; competência digital; aprender a aprender; competências sociais e cívicas; espírito de iniciativa; consciência e expressão cultural. Essas competências se entrelaçam para a formação da criatividade, do espírito crítico; da capacidade de iniciativa, da resolução de problemas e da avaliação de riscos 
Na América Latina, o Acordo de Bologna se irradia no Projeto Alfa-Tuning América Latina, de 2002, seguindo as mesmas orientações, cujo propósito é "aperfeiçoar as estruturas educativas da América Latina" quanto a oferta de títulos, conhecimentos, habilidades e níveis de compreensão dos concluintes; trocar informações sobre as competências - incluindo destrezas, conhecimentos e conteúdo; e intensificar a colaboração entre IES quanto ao desenvolvimento dos currículos, sua qualidade e eficácia. ${ }^{13}$

O discurso que fundamenta a formação por competência pode encontrar na cultura profissional do Serviço Social uma ambientação favorável à sua difusão em decorrência de seus vínculos com a empiria e certa mitificação da "prática profissional". Considerando a dimensão teórico-prática da profissão, é fácil associar as competências específicas por ela requeridas à integração entre o saber, o saber-fazer e o saber ser. Acompanha-as $a$ valorização das experiências vividas e da própria subjetividade no exercício cotidiano. Pode-se resvalar no perfil conservador das "tecnologias sociais voltadas ao desenvolvimento", em detrimento de uma formação acadêmica de maior solidez, discurso este favorável aos reclamos do "mercado" num contexto de crise.

A crise financeira recente se desencadeia na Europa, em 2007, desdobra-se na falência do Banco Lehman, em 2008, e espraia-se também na zona do euro. É a expressão, na esfera das finanças, da situação de estagnação da economia mundial. O substrato da crise reside, segundo Chesnais (2013), no superpoder das instituições financeiras, na superprodução e na superacumulação de capacidades de produção especialmente elevadas em um contexto de intensa concorrência intercapitalista. É acompanhada de uma acumulação de capital fictício sem precedentes, às quais se aliam a difícil situação dos trabalhadores em qualquer parte do mundo. Nas épocas de crise, o capital (incluindo os governos, bancos centrais, Fundo Monetário Internacional, centros privados de centralização de poder e de capital) ficam emperrados em suas próprias contradições, enfrentando barreiras

\footnotetext{
para a tomada de decisões. b) As competências genéricas ou transversais são comuns a várias ocupações ou profissões: domínio das tecnologias de comunicação e informação, comunicação escrita e oral, atuação em equipe e adaptabilidade a mudanças. c) As competências técnicas ou especificas são aquelas desenvolvidas com a especialização e são próprias de determinada profissão ou ocupação.

13. O debate da formação por competências deixa suas marcas na orientação do Conselho Nacional de Educação referente às diretrizes curriculares flexíveis e com ênfase na dimensão prática da formação universitária. A valorização das competências tem repercussão no Plano Nacional de Pós-Graduação 2011-2020 do país (cf. Brasil, 2010).
} 
por ele criadas, como alerta Chesnais (2013). Em outros termos, como sintetiza Behring (2010), a crise é parte constitutiva do movimento do capital e não uma disfunção ou problema de regulação.

Num contexto em que bancos, empresas industriais e de serviços cada vez mais se internacionalizam, também as universidades vivem esse processo. Cresce a concorrência entre oligopólios — que também atuam no ensino superior fruto da acelerada concentração e centralização de capitais cuja expansão ultrapassa fronteiras nacionais. Sabe-se que concorrência é acirrada nos momentos de crise, quando o suporte dos Estados nacionais se mostra fundamental para o socorro aos capitais e para cumprir compromissos assumidos com os agentes financeiros, decorrentes da dívida pública. Os serviços da dívida - juros e taxas — transferem, por meio de impostos, uma imensa massa de valor e mais-valia - isto é, da riqueza socialmente criada - para os agentes financeiros, especialmente os fundos de aplicação e os bancos: o chamado "mercado", cujos interesses se sobrepõem a todos os demais, em detrimento dos interesses da coletividade. Ao mesmo tempo em que cresce a superexploração dos trabalhadores ativos, amplia-se a superpopulação relativa para as necessidades médias de valorização capitalista e impulsiona-se a pilhagem de recursos naturais do planeta para alimentar a sede insaciável de "fazer dinheiro" (Idem).

Ante a redução do padrão de vida dos trabalhadores e o crescimento de desigualdades, aumentam os conclames ao "aproveitamento de oportunidades" (supostamente iguais para todos) ofertadas pelo "mercado". Ele é indissociável da responsabilização dos trabalhadores e suas famílias pela melhoria das próprias condições de vida mediante estratégias de empoderamento dos indivíduos vulneráveis, culpabilizados e criminalizados por sua própria pobreza, isentando a sociedade do capital da responsabilidade pela produção ampliada de desigualdades, as quais se transformam em "alavancas para a competitividade". Esse quadro atinge transversalmente o ensino superior, alterando as condições da formação acadêmica e do exercício profissional na contemporaneidade.

\section{A formação acadêmico-profissional na atualidade}

A formação acadêmico-profissional em Serviço Social no Brasil sofre importantes mutações na atualidade em decorrência de: (a) expansão acelerada da oferta de vagas, como já relatado; (b) prevalência de instituições de ensino privadas não 
universitárias em detrimento das universidades, o que coloca em questão o tripé ensino, pesquisa e extensão como base da formação, visto estar associado às funções precípuas da instituição universitária; (c) precarização das condições de trabalho docente expressa na proliferação de contrato por tempo determinado ou por tarefa, no rebaixamento salarial, na intensificação do trabalho, no maior volume de aulas semanais com elevada relação numérica professor/aluno, na redução da autonomia docente na elaboração dos programas das disciplinas, em favor de pacotes preestabelecidos pelas empresas que definem conteúdos e bibliografias adotados; absorção de pós-graduandos, que buscam acumular experiência no trabalho docente; (d) mudança no perfil socioeconômico dos estudantes, com ampliação do acesso aos IES por parte da juventude trabalhadora, estimulada pela política de cotas para o ensino superior, bolsas do ProUni, crédito escolar, entre outros. Observa-se maior incorporação de trabalhadores economicamente ativos que buscam no ensino superior meios de ascensão social e de elevação de status social na unidade familiar.

Ainda que a profissão e o ensino acadêmico-profissional tenham se secularizado ao longo dos anos, a religiosidade impregna a juventude estudantil na área, especialmente a de raiz protestante. Ela hoje prevalece sobre a influência da Igreja católica, que teve dominância ideológica no passado dessa área profissional. O componente religioso atualmente é mais afinado com a ascensão social capitalista, expressando um trânsito da fraternidade à prosperidade. Verifica-se, simultaneamente, uma alteração na composição de classe do contingente profissional, reduzindo a distância social entre a categoria de assistentes sociais e o público atendido, com refrações no universo cultural dos estudantes, o que merece atenção por parte das unidades formadoras. Por outro lado, a metamorfose na situação de classe dos estudantes cria uma ambientação favorável, apoiada na experiência de vida, à identificação com os dilemas do conjunto da classe, alvo predominante dos serviços profissionais e das políticas sociais públicas. Assim, pode também representar para o profissional um reforço à identidade de classe enquanto trabalhador, matizada por recortes de gênero, etnia e geração.

$\mathrm{O}$ desmesurado crescimento do quadro profissional nas últimas décadas, decorrente da expansão acelerada do ensino superior privado — em particular no ensino à distância - tem implicações na qualidade acadêmica da formação, no aligeiramento no trato da teoria, na ênfase no treinamento e menos na descoberta científica. A massificação e a perda de qualidade da formação universitária facilitam a submissão dos profissionais às demandas e "normas do mercado", tendentes a um processo de politização à direita da categoria. O aumento do contingente 
profissional vem acompanhado de crescimento do desemprego em uma conjuntura recessiva, pressionando o piso salarial e a precarização das condições de trabalho, aumentando a insegurança no emprego e a concorrência no mercado profissional de trabalho. Dificilmente a oferta de trabalho poderá acompanhar, no mesmo ritmo, o crescimento do número de profissionais, podendo desdobrar-se na criação de um exército assistencial de reserva, como recurso de qualificação do "voluntariado", e no reforço ao clientelismo político, aos chamamentos à "solidariedade" enquanto estratégia de obscurecimento das clivagens de classe.

Segundo informações da Abepss ${ }^{14}$ em relação ao projeto de formação acadêmico-profissional reclama-se a necessidade de aprofundamento teórico-metodológico das matrizes de análise, especialmente do método crítico dialético e respectivo acervo categorial; do significado dos núcleos como estruturantes da formação; dos fundamentos do Serviço Social, articulando as dimensões de história, teoria e método; a necessidade de reforço de conteúdos relativos à formação social brasileira, a compreensão da transversalidade da ética e da pesquisa e o estágio supervisionado.

No campo da pesquisa e da produção de conhecimentos referente aos fundamentos históricos e teórico-metodológicos do Serviço Social, dentre os seus avanços vale relembrar estudos já consolidados referentes às relações entre Estado e a sociedade no âmbito das políticas públicas — em especial das políticas sociais —, terreno contraditório de forças sociais no qual se inscreve majoritariamente a atuação do assistente social em resposta às múltiplas expressões da "questão social". A ênfase recai na implementação, gestão, avaliação e financiamento de programas e projetos sociais previstos pelas políticas públicas — com privilégio da seguridade social, em especial saúde e assistência - , contribuindo para qualificar o debate sobre o trabalho do assistente social. Verifica-se clara preocupação em relacionar as políticas públicas e os sujeitos sociais na mobilização por direitos e/ou em sua representação nos órgãos de controle democrático do Estado, via Conselhos de Políticas e de Direitos. A análise dos sujeitos sociais vem sendo filtrada pelas fragmentações operadas pelas políticas no atendimento às necessidades sociais das classes subalternas e seus segmentos — idosos, crianças e adolescentes, portadores de necessidades especiais etc. —, nem sempre atribuindo visibilidade às clivagens coletivas de classe.

14. Relatório da Abepss Itinerante - gestão 2011-12, Abepss-Leste. Agradeço a ex-presidente da Abepss, profa. dra. Cláudia Mônica dos Santos, o acesso ao referido relatório. 
Os estudos sobre os processos de reestruturação produtiva, relações e processos de trabalho têm sido complementados com a pesquisa sobre a diversidade das formas de organização dos trabalhos e perfis de segmentos dos trabalhadores, além de estudos sobre o mercado de trabalho. Destacam-se, ainda, estudos sobre cultura, identidades e subjetividades dos sujeitos, considerando a família, a sociabilidade e o cotidiano dos sujeitos, em seus recortes econômicos, políticos, de gênero, etnia e geração. Relativamente de menor alcance têm sido os investimentos em pesquisas sobre conflitos e movimentos sociais, processos organizativos e mobilização popular. Reclama-se maior acompanhamento do cotidiano dos conflitos de distintos segmentos das classes subalternas, assim como a reconstituição da memória de suas lutas.

No marco do universo da trajetória do Serviço Social, verifica-se a carência de críticas teóricas substantivas do Serviço Social clássico e seus principais formuladores, para além da denúncia genérica de seus vínculos teórico-práticos com o conservadorismo. A crítica aos fundamentos do Serviço Social de caso, do Serviço Social de grupo e do Serviço Social de comunidade - considerando também os debates internos entre autores clássicos no interior de cada uma dessas propostas de ação profissional - , parece-nos da maior importância, na atualidade, em um duplo sentido: a) para criar subsídios teórico-metodológicos na resistência à onda cultural conservadora, que faz ressurgir abordagens individuais, grupais e comunitárias em seus fundamentos liberais e conservadores; b) e para estabelecer bases para um diálogo crítico com o Serviço Social internacional - em especial o europeu e o norte-americano - , amplamente fundado em tais abordagens. Verifica-se o ressurgimento da noção de "comunidade" por parte discurso oficial de governos e de organismos internacionais, frequentemente incorporado e reproduzido por segmentos de assistentes sociais.

É necessário dar prosseguimento, com maior rigor e profundidade, à apropriação do arco de vertentes teóricas que vêm marcando presença no debate profissional brasileiro e latino-americano dos anos 1980 à atualidade. Essa apropriação supõe o tratamento crítico de categorias e princípios metodológicos dessas vertentes, considerando também as particularidades históricas nacionais no debate profissional. O rarefeito acervo de análises substantivas e rigorosas na literatura especializada latino-americana sobre o movimento de reconceituação nos países de lingua espanhola e no Brasil, salientando particularidades nacionais e considerando a diversidade de suas expressões e suas heranças históricas e teóricas.

Constata-se a ausência de tradição de pesquisas sobre o Serviço Social internacional (incluindo uma viva interlocução com o Serviço Social latino-ameri- 
cano) em particular em relação aos países hispânicos e lusófonos. Reclama-se maior aproximação ao debate acadêmico sobre o Serviço Social internacional, tanto do ensino de graduação quanto nos programas de pós-graduação. ${ }^{15}$

Verifica-se a necessidade de dar continuidade aos estudos sobre o processamento do trabalho cotidiano do assistente social na efetivação das competências e atribuições profissionais e às estratégias para sua implementação.

A ênfase nos estudos históricos sobre o Brasil contemporâneo é indispensável ao acompanhamento das mudanças macrossocietárias e suas expressões conjunturais, subsidiando a leitura das forças e sujeitos sociais que incidem no exercício profissional, condição para elucidar o seu significado social na sociedade nacional. Dentre os núcleos norteadores da formação acadêmico profissional, o menor investimento coletivo direcionou-se ao tema das particularidades da formação brasileira e do contexto latino-americano, envolvendo a compreensão da diversidade regional, das classes sociais e seus segmentos, da questão agrária, dos processos migratórios, das populações tradicionais, das cidades, entre inúmeras outras dimensões, salientando suas implicações para o Serviço Social.

Há ainda muito a elucidar sobre os dilemas clássicos da prática política que, por meio de mediações particulares, se atualizam no trabalho profissional, dotado de uma incontornável dimensão política: o burocratismo, o basismo, o espontaneísmo, o reformismo, entre outros, que já dispõem de um lastro analítico no campo da teoria política e, frequentemente, se repõem no exercício profissional.

É necessário dar continuidade à pesquisas, já em andamento, sobre as metamorfoses no mercado de trabalho e nos espaços ocupacionais do assistente social nos âmbitos do Estado e respectivas políticas públicas, das empresas capitalistas e organizações civis não lucrativas, com especial ênfase nas respostas profissionais e nas relações estabelecidas com os segmentos de trabalhadores que demandam as políticas e serviços. Em um contexto recessivo, os assistentes sociais também sofrem a desregulamentação do trabalho formal, a perda do acesso aos direitos trabalhistas e do salário indireto, os rebaixamentos salariais. Cresce o trabalho

15. Hoje existe uma articulação do Serviço Social latino-americano por meio da Associação Latino-Americana de Ensino e Investigação em Trabalho Social (Alaeits), do Comitê Mercosul, criado em 1996, e, atualmente do Comitê Latinoamericano y Caribeño de Organizaciones Profesionales de Trabajo Social/ Servicio Social (Colacats). Mas ressente-se também de uma sólida articulação do Serviço Social nos países lusófonos e de língua hispânica, e uma maior aproximação ao Serviço Social radical que vem recentemente se rearticulando no cenário europeu, em especial o anglo-saxônico. 
precário, temporário, a contratação por projetos, que geram: insegurança da vida dos profissionais mediante a ausência de horizonte de largo prazo de emprego e a perda de direitos. A ameaça de desemprego e a experiência do desemprego temporário afetam diretamente a sobrevivência material e social do assistente social, que depende da venda de sua força de trabalho para a obtenção de meios de vida, como qualquer trabalhador assalariado. Essa precarização das condições de trabalho atinge a qualidade dos serviços prestados e a relação com a população; projetos são abruptamente interrompidos quando termina o seu financiamento temporário; expectativas da população envolvida nas atividades são frustradas, a legitimidade obtida para realização do trabalho do assistente social é truncada, além de outras incidências de ordem ética.

$\mathrm{Na}$ esfera pública, os atuais 5.570 municípios brasileiros são os que mais absorvem assistentes sociais, especialmente por meio da Política Nacional de Assistência Social (PNAS). É necessário salientar as particularidades da atuação nos pequenos municípios com menos de vinte mil habitantes. Aí os profissionais são sujeitos a maior polivalência no nivel das demandas, à precariedade de recursos materiais que afetam as condições básicas de trabalho, assim como a maior ingerência das forças políticas locais no trabalho cotidiano. Alia-se a existência de fronteiras pouco nítidas entre o público e o privado que têm lugar na cultura política brasileira, favorecendo os clientelismos, patrimonialismos e coronelismos contemporâneos.

No nível federal, os concursos públicos são importantes conquistas dos anos recentes, a exemplo do Ministério da Previdência Social, com a contratação maciça de cerca de novecentos assistentes sociais, assim como a construção de carreira profissional no Estado, a exemplo da NOB-RH (2006), do Sistema Único de Assistência Social (Suas) no Ministério do Desenvolvimento Social e Combate à Fome. Apesar da normatização legal, são registradas diferentes formas contratuais, por vezes convivendo no mesmo espaço ocupacional: profissionais concursados, contratados por tempo determinado, destituídos de direitos trabalhistas, terceirização de serviços etc., que denotam a precarização de vínculos e direitos trabalhistas (Raichelis, 2011, 2013; Alencar e Granemann, 2009; Santos, 2010). Por outro lado, o Estado também vem impulsionando a terceirização na execução de políticas públicas, transferidas para as organizações não governamentais e/ou empresas privadas, financiadas integral ou parcialmente com o fundo público, configurando espaços ocupacionais com elevados índices de precarização. Nesses espaços ocupacionais os assistentes sociais exercem as competências e atribuições resguardadas 
por lei (CFESS, 2002; Iamamoto, 2002) e reafirmadas nas diretrizes curriculares, cuja qualificação vem sendo objeto de atenção de parte da categoria (Bravo, 2009; Amaral e Cesar, 2009, Raichelis, 2009; Faleiros, 1987; Cardoso e Lopes, 2009).

São muitos os desafios ao Serviço Social, dentre os quais:

1. Dar continuidade aos estudos sobre as incidências da política de educação superior - em suas tendências de crescente e privatização e mercantilização - no trabalho docente, no nível da formação acadêmica, na submissão do conhecimento às demandas do mercado e na alienação das atividades do pesquisador.

2. Zelar pelo aperfeiçoamento da qualificação teórico-metodológica e ético-política dos assistentes sociais, denunciando o aligeiramento da formação profissional decorrente da subordinação da educação superior à lógica da lucratividade.

3. Aprofundar a pesquisa sobre as vertentes teórico-metodológicas que têm marcado presença no debate profissional a partir do período 1980-90.

4. Apoiar o diálogo acadêmico respeitoso e plural entre as diferentes perspectivas de leitura e análise da profissão no cenário mundial, afirmando sua dimensão educativa e seu compromisso com os direitos humanos e a justiça social.

5. Estimular pesquisas sobre as metamorfoses do mercado de trabalho e dos espaços ocupacionais do assistente social nos âmbitos do Estado bem como das empresas capitalistas e organizações civis não lucrativas.

6. Cultivar uma atitude crítica e ofensiva na defesa das condições de trabalho do assistente social e da qualidade dos atendimentos, potenciando a nossa autonomia profissional segundo os preceitos éticos que regem o exercício profissional.

7. Impulsionar estudos históricos sobre a formação sócio-histórica do Brasil e a América Latina, favorecendo estudos comparados.

8. Analisar as mudanças observadas no perfil do sujeito profissional a partir dos anos 1990: quem é o assistente social hoje?

9. Enriquecer a pesquisa sobre os sujeitos sociais que são o alvo privilegiado das ações profissionais - os segmentos da classe trabalhadora em seus recortes de gênero, etnia, geração, território - , enfrentando as abordagens focalizadas e individuais que obscurecem a sua dimensão coletiva. 
Termino com a poesia de Milton Nascimento:

\author{
"Se muito vale o já feito \\ Mais vale o que será \\ E o que foi feito é preciso \\ Conhecer para melhor prosseguir \\ [...] Outros outubros virão \\ Outras manhãs plenas de luz e de sol".
}

Recebido em: 8/8/2014 - Aprovado em: 13/8/2014

\title{
Referências bibliográficas
}

ABESS/CEDEPSS. Proposta básica para o projeto de formação profissional. Serviço Social \& Sociedade: O Serviço Social no século XXI, São Paulo, ano XVII, n. 50, p. 143-171, abr. 1996.

. Diretrizes gerais para o curso de Serviço Social. (Com base no currículo mínimo aprovado em Assembleia Geral Extraordinária de 08 de novembro de 1996). Formação Profissional: Trajetória e Desafios. Cadernos ABESS, São Paulo, n. 7, p. 58-76, 1997 a. Edição especial.

. Proposta básica para o projeto de formação profissional. Novos subsídios para o debate. Cadernos Abess, São Paulo, n. 7, p. 15-58, $1997 \mathrm{~b}$.

ABEPSS. Formação do assistente social no Brasil e a consolidação do projeto ético-político. Serviço Social \& Sociedade. Especial: Serviço Social: formação e projeto político. São Paulo, ano XXV, n. 79, p. 72-81, set. 2004.

. Pesquisa avaliativa da implementação das diretrizes curriculares do curso de Serviço Social. Relatório Final. São Luís, 2008. [CD-ROOM.]

. Projeto ABEPSS Itinerante: as diretrizes curriculares e o projeto de formação profissional do Serviço Social. Juiz de Fora, 2011.

. Relatório da ABEPSS Itinerante, gestão 2011-12. Abepss-Leste.

ALENCAR, M. M. T.; GRANEMANN, S. Ofensiva do capital e as novas determinações do trabalho profissional. Kalálysis, Florianópolis, v. 12, n. 2, p. 161-169, jul./dez. 2009. 
AMARAL, A. S.; CÉSAR, M. O trabalho do assistente social nas empresas capitalistas. In: CFESS. Serviço Social: direitos sociais e competências profissionais. Brasília: CFESS, 2009. p. 411-428.

BANCO MUNDIAL. Construir sociedades de conocimiento: nuevos desafios para la educación terciaria. Washington, 2003. Disponível em: <http://www.bancomundial.org.br>. Acesso em: set. 2010.

BAPTISTA, M. V.; RODRIGUES, M. L. A formação pós-graduada stricto sensu em Serviço Social: papel da pós-graduação na formação profissional e desenvolvimento do Serviço Social. Cadernos Abess, São Paulo, n. 5, p. 108-136, 1992.

BRASIL. Resolução CNE/CES n. 15, de 13 de março de 2002. Estabelece as Diretrizes Curriculares para os cursos de Serviço Social. Disponível em: $<$ http://portal.mec.gov.br/cne/ arquivos/pdf/CES152002.pdf $>$. Acesso em: 24 ago. 2014.

. Ministério da Educação. Coordenação de Aperfeiçoamento de Pessoal de Nível Superior. Plano Nacional de Pós-Graduação (PNPG, 2011-2020). Coordenação de Pessoal de Nível Superior. Brasília: Capes, 2010. 2 v.

BEHRING, E. Crise do capital, fundo público e valor. In: BOSCHETTI, I. et al. Capitalismo em crise: Política social e direitos. São Paulo: Cortez, 2010. p. 13-34.

BRAVO, M. I. O trabalho do assistente social nas instâncias públicas de controle democrático. In: CFESS. Direitos sociais e competências profissionais. Brasília: CFESS, 2009. p. 411-428.

CAPES. Mestrados e doutorados reconhecidos. Disponível em: $<$ http://conteudoweb.capes. gov.br/conteudoweb/ProjetoRelacaoCursosServlet?acao=pesquisarArea\&identificad or $=32 \#>$. Acesso em: 20 ago. 2014.

CARDOSO, F. G.; LOPES, J. B. O trabalho dos assistentes sociais nas organizações da classe trabalhadora. In: CFESS. Direitos sociais e competências profissionais. Brasília: CFESS, 2009. p. 411-428.

CARVALHO, A. M. et al. Projeto de investigação: a formação profissional do assistente social no Brasil: determinantes históricos e perspectivas. Serviço Social \& Sociedade, São Paulo, n. 14, 1984.

CFESS. Comissão de Fiscalização. Atribuições privativas do(a) assistente social em questão. 1. ed. ampl. Brasília: CFESS, 2012a.

. Comissão de Fiscalização. Atribuições privativas do(a) assistente social em questão. Brasília: CFESS, fev. 2002.

. Atribuições privativas do(a) assistente social em questão. 1. ed. ampl. Brasília: CFESS, 2012a. 
CFESS. Comissão de Fiscalização. Subsidios para a atuação de assistentes sociais na política de educação. Social. Série Trabalho e projeto profissional nas políticas sociais, n. 3 . Brasília: CFESS, 2010.

. Direito se conquista: a luta dos/as assistentes sociais pelas 30 horas semanais. Brasília, CFESS, 2011.

. II Seminário Nacional. O Serviço Social no campo sociojurídico na perspectiva da concretização de direitos. Brasília: CFESS, 2012 b.

. Conselho Federal de Serviço Social. Parâmetros para atuação de assistentes sociais na politica de assistência social. Série Trabalho e projeto profissional nas políticas sociais, Brasília: CFESS, n. 1, 2013a (reimpressão).

. Parâmetros para atuação de assistentes sociais na política de saúde. Série Trabalho e projeto profissional nas políticas sociais. Brasília: CFESS, n. 2, 2013b (reimpressão).

. CFESS é eleito para coordenação do Colacats. Disponível em: $<$ http://www.cfess. org.br/visualizar/noticia/cod/1077>. Acesso em: 6 ago. 2014.

CHAUI, M. Em torno da universidade de resultados e de serviços. Revista USP. Dossiê Universidade Empresa, São Paulo, n. 25, p. 54-61, mar./maio 1995.

. Reforma do ensino superior e autonomia universitária. Serviço Social \& Sociedade.

20 anos. São Paulo, n. 61, p. 118-126, nov. 1999.

CHESNAIS, F. As raízes da crise econômica mundial. Em Pauta, Rio de Janeiro, n. 31, v. 11, p. 21-37, 1. sem. 2013.

FALEIROS, V. P. Saber profissional e poder institucional. São Paulo: Cortez, 1987.

FLEURY, M. T. L.; FLEURY, A. C. C. Construindo o conceito de competência. Revista de Administração Contemporânea, Curitiba, v. 5. Disponível em: $<$ http://www.scielo.br/scielo. php?pid=S1415-65552001000500010\&script=sci_arttext $>$. Acesso em: 20 ago. 2014.

IAMAMOTO, M. V. Proposta de interpretação histórico-metodológica. In: ; CAR-

VALHO, R. Relações sociais e Serviço Social no Brasil: esboço de uma interpretação histórico-sociológica. São Paulo: Cortez/Celats, 1982.

. Projeto profissional, espaços ocupacionais e trabalho do(a) assistente social na atualidade. In: CFESS. Comissão de Fiscalização. Atribuições privativas do(a) assistente social em questão. Brasília: CFESS, fev. 2002. p. 13-50.

. Serviço Social em tempo de capital fetiche: capital financeiro, trabalho e questão social. São Paulo: Cortez, 2007.

; CARVAlHO, R. Relações sociais e Serviço Social no Brasil. São Paulo: Cortez/ Celats, 1982. 
IANNI, O. A ideia do Brasil moderno. São Paulo: Brasiliense, 1992. p. 87-109. . Pensamento social no Brasil. Bauru: Edusc, 2004.

IFSW. What we do. Disponível em: <http://ifsw.org/what-we-do>. Acesso em: 6 set. 2013. MARX, K. Crítica da filosofia do direito de Hegel. Introdução. São Paulo: Grijalbo, 1977. p. 1-14. (Col. Temas de Ciências Humanas, n. 2.)

. Introdução à crítica da economia política (1857). In: Marx. São Paulo: Abril Cultural, 1974. p. 107-138. (Col. Os Pensadores.)

MANDEL, E. O capitalismo tardio. São Paulo: Nova Cultural, 1985.

MEC-SESU. Coordenação da Comissão de Especialistas de Ensino. Comissão de Especialistas de Ensino (CCEE). Comissão de Especialistas de Ensino em Serviço Social (Coness). Diretrizes Curriculares. Curso Serviço Social. Brasília, fevereiro de 1999. Disponível em: http://www.cfess.org.br/arquivos/legislacao_diretrizes.pdf>. Acesso em: 24 jul. 2014.

NETTO, J. P. Transformações societárias e Serviço Social: notas para uma análise prospectiva da profissão. Serviço Social \& Sociedade, São Paulo, n. 50, p. 87-132, 1996.

. Cinco notas a propósito da questão social. Temporalis, Brasília, Abepss, n. 3, p. 4145, 2001.

ORTIZ, F. G. Notas sobre as diretrizes curriculares; avanços, impasses e desafios. In: GUERRA, Y.; LEITE. 1.; ORTIZ, F. G. Temas contemporâneos: o Serviço Social em foco. São Paulo: Outras Expressões, 2013. p. 11-31.

RAICHELIS, R. O trabalho do assistente social na esfera estatal. Direitos sociais e competências profissionais. Brasília: CFESS, 2009. p. 377-392.

. O assistente social como trabalhador assalariado: desafios frente à violação de seus direitos. Serviço Social \& Sociedade. São Paulo, n. 107, p. 420-437, jul./set. 2011.

. Proteção social e trabalho do assistente social: tendências e disputas na conjuntura de crise mundial. Serviço Social \& Sociedade, São Paulo, n. 116, p. 609-635, out./dez. 2013.

RAMOS, M. Nogueira. Currículo por competências. Disponível em: <http://ead.esp.mg. gov.br/nte/docs/competencias_tela10.pdf>. Acesso em: 6 ago. 2014.

SANTOS, M. B. J. O trabalho do assistente social no Suas: relações de trabalho e competências profissionais. In: MOTA, A. E. (Org.). As ideologias da contrarreforma e o Serviço Social. Recife: Ed. da UFRPE, 2010, p. 383-437.

RAMOS, Marise Nogueira. Currículo por competências. In: PEREIRA, Isabel Brasil; LIMA, Júlio César França (Orgs.). Dicionário da educação profissional em saúde. 2. ed. Rio de 
Janeiro: EPSJV, 2008. Disponível em: <http://ead.esp.mg.gov.br/nte/docs/competencias tela10.pdf>. Acesso em: 6 ago. 2014.

. A pedagogia das competências: autonomia ou adaptação. São Paulo: Cortez. 2001.

. A educação profissional pela pedagogia das competências e a superfície dos documentos oficiais. Educação \& Sociedade, Campinas, v. 23, n. 80, p. 401-422, set. 2002.

WERNER, R. Desafios contemporâneos da formação profissional e desenvolvimento de competências e habilidades no Serviço Social. São Paulo: PUC-SP, 2010.

YAZBEK, M. C. (Org.). Projeto de revisão curricular da Faculdade de Serviço Social da PUC-SP. Serviço Social \& Sociedade, São Paulo, n. 14, 1984.

\section{Fontes eletrônicas:}

Disponível em: <http://ifsw.org/what-we-do/>. Acesso em: 6 set. 2013.

Disponível em: <http://www.cfess.org.br/visualizar/noticia/cod/1077> . Acesso em: 6 ago. 2014.

Disponível em: <http://conteudoweb.capes.gov.br/conteudoweb/ProjetoRelacaoCursosSer vlet? $\mathrm{acao}=$ pesquisarArea\&identificador=32\#>. Acesso em: 20 ago. 2014. 